\title{
Same-different judgments of multiletter strings: Insensitivity to positional bias and spacing
}

\author{
ROBERT W. PROCTOR \\ Purdue University, West Lafayette, Indiana \\ ALICE F. HEALY \\ University of Colorado, Boulder, Colorado \\ and \\ TRISHA VAN ZANDT \\ Purdue University, West Lafayette, Indiana
}

\begin{abstract}
Several recent studies of multiletter matching have included pairs of strings that have the same letters in different positions (rearranged pairs). The task can be defined such that these rearranged pairs are correctly classified as different (i.e., subjects respond "same" only if the strings have the same letters in the same positions-the order task) or as same (i.e., subjects respond "same" if the strings have the same letters regardless of their positions-the item task). The order task produces left-to-right serial-position effects, whereas the item task produces U-shaped serialposition effects. Because these differences suggest that subjects may be able to exert strategic control over the comparison process, two sets of experiments were designed to test whether or not subjects can change the relative weightings devoted to the respective serial positions. In Experiments 1 and 2 , the probability that a mismatch occurred in the different positions was manipulated. In Experiments 3 and 4, the physical spacing between letters, as well as whether or not the spaces were filled with neutral noise characters, was varied. None of the manipulations had much influence on the serial-position effects. Thus, the distinct serial-position effects for the order and item tasks apparently are mandatory and not due to any voluntary comparison strategy.
\end{abstract}

Numerous studies have investigated same-different matching for pairs of multiletter strings. In many of the models proposed to account for a variety of findings from these studies, it has been presumed that accumulation of pooled perceptual information feeds into a response process (Krueger, 1978; Ratcliff, 1981; Vickers, 1979). The response process includes criteria that determine the amount of similarity or difference to which the information must build before one of the two responses is selected. Consistent with such accumulation models, subjects can trade speed for accuracy when a deadline is imposed (Krueger \& Chignell, 1985), suggesting a drop in the criterial amount of information required to select a response. Moreover, subjects can adjust the relative accuracies and latencies for the same and different responses

This research was supported in part by Grant 88-0002 from the Cognition Program of the Air Force Office of Scientific Research to Auburn University and by United States Army Research Institute Contracts MDA 903-86-K-0155 and MDA 903-90-K-0066 to the Institute of Cognitive Science at the University of Colorado. We would like to thank Antoinette Gesi for help with testing subjects and performing data analyses for Experiments 3 and 4, and David Fendrich for assisting with the data analyses for Experiment 4 . The manuscript benefited from the comments of Philip Allen, Bart Farell, Lester Krueger, and an anonymous reviewer on an earlier draft. Correspondence concerning this article should be addressed to Robert W. Proctor, Department of Psychological Sciences, Purdue University, West Lafayette, IN 47907. when biases are induced through instructions or probability manipulations (Proctor \& Rao, 1983; Proctor, Rao, \& Hurst, 1984; Proctor \& Weeks, 1989; Ratcliff \& Hacker, 1981), implicating adjustments in the relative levels of the same and different response criteria.

Other evidence suggests that with the exception of response criteria, subjects have little control over the matching process. It is well documented that same-different judgments are affected systematically by irrelevant stimuli or stimulus attributes, such as extraneous letters (Eriksen, O'Hara, \& Eriksen, 1982), size differences (Watson, 1981), and orientational differences (Ambler \& Proctor, 1976). Moreover, differences obtained between situations in which the irrelevant attribute is held constant within blocks of trials and those in which it varies are explainable in terms of relative criteria settings. In the latter situations, subjects adopt compromise criteria to maximize performance on the trials on which they will tend to be more error-prone (Carr, Posner, Pollatsek, \& Snyder, 1979; Krueger, 1985; Proctor, Van Zandt, \& Watson, 1990).

Two variants of the matching task that have been investigated during the past decade involve the use of pairs of multiletter strings that have the same letters in different orders (rearranged pairs). The primary finding in these tasks is that reaction time (RT) and accuracy vary systematically as a function of the number of positions over which the letters in one string are displaced to form the 
other. When the task is to respond "same" only if the two strings contain the same letters in the same positions (the order task), different responses to the rearranged pairs become faster and more accurate as displacement increases (Ratcliff, 1981; Ratcliff \& Hacker, 1981). In contrast, when the task is to respond "same" if the two strings contain the same letters regardless of their positions (the item task), same responses to the rearranged pairs become slower and less accurate with increasing displacement (Angiolillo-Bent \& Rips, 1982).

The results obtained with the order and item tasks generally seem consistent with previous findings that the principal means by which subjects control matching-task performance consists of adjustments in response criteria. For example, the overall level of accuracy for same and different responses in the order task becomes progressively less as shorter and shorter RT windows are imposed (Ratcliff, 1981). Moreover, when the proportions of same and different pairs are varied, same and different RTs and errors are traded off in a manner consistent with the alteration of response criteria (Proctor \& Healy, 1987).

A lack of control over other aspects of the matching process is indicated by the finding that a displacement effect is obtained for the order task. That is, even though between-position comparisons are not pertinent to the same-different decision in this task, and thus should be ignored, they still affect performance. Because the displacement effect for the order task is qualitatively and quantitatively similar to that for the item task (though in the reverse direction) when either three-letter or four-letter strings are compared (Proctor \& Healy, 1985, 1987), the between-position comparisons seem to be given equivalent weighting regardless of whether or not they are relevant. Thus, the results from the order and item tasks are in accord with the accumulation models and indicate that between-position comparisons provide part of the information that specifies similarity and difference.

Although the results of the order and item tasks are consistent with the view that subjects mainly control the values of the response criteria, other evidence from these tasks suggests that the comparison process itself may be controllable. Despite the overall similarity of the displacement effects for the two tasks, the order task consistently shows a greater left-to-right weighting of serial positions than does the item task. Responses to rearranged pairs in the order task are slower and less accurate when they match in the leftmost position, while responses to pairs for which the two strings have all but one letter in common become progressively slower and less accurate as the mismatch is moved from the leftmost to the rightmost position (Proctor \& Healy, 1985, 1987).

To account for the results from the order and item tasks, Proctor and Healy (1987) proposed a position-sensitive comparison model in which information toward same or different consists of the pooled output from comparisons of the component letters. According to the model, each letter in one string is compared in parallel with each letter in the other string, with the weightings of the compo- nent comparisons being a decreasing function of positional displacement. The distinct serial-position effects for the order and item tasks were interpreted as suggesting that subjects can control the weights given to different parts of the mental representation of the stimuli. In the order task, subjects apparently choose to weight the items at the left end of the representation most heavily in the comparison. This interpretation attributes the task-specific serial-position effects to changes in strategy that are under subjects' control. However, this proposal conflicts with the other evidence from matching tasks that indicates that subjects seem unable to control crucial aspects of the matching process.

The present study was designed to evaluate the extent to which subjects can control the weighting processes used in the performance of the order and item tasks. If the different serial-position effects for the two tasks reflect strategic control, then changes in the stimuli designed to encourage specific within-position comparisons or to discourage between-position comparisons should induce further dissociations between the order and item tasks. If subjects can only control the response criteria that are used for the same-different decision, then these manipulations should have little effect, and any effect should be comparable for the two tasks.

In Experiments 1 and 2, the percentages of trials on which a mismatching letter occurred in the left, center, or right position were varied for pairs of three-letter strings. These unequal presentation probabilities introduce specific positional biases that should be used to optimize performance if the weightings of the respective positions are under subjects' control. That is, greater weights should be given to the within-position comparisons for which mismatches are most likely. In Experiments 3 and 4, the physical spacing between letters and the presence of extraneous noise items were varied. Physical separation of the letters by either of these means should prevent unnecessary between-position comparisons if the weighting of these comparisons is under subjects' control.

\section{EXPERIMENTS 1 AND 2}

In the methods used by Proctor and Healy $(1985,1987)$, three types of pairs are presented. For identical pairs, the strings have the same letters in the same positions. The letters in the two strings also are the same for rearranged pairs, but the letters in one string are displaced relative to those in the other. Replacement pairs are constructed from the identical and rearranged pairs, but they include a single letter that differs between the two strings.

The order task shows an exaggerated left-to-right serialposition effect relative to the item task when replacement letters are equally likely in all positions (Proctor \& Healy, 1987). It is well known that presentation probabilities systematically affect RTs in visual search and detection (see, e.g., Shaw, 1982; Theios, Smith, Haviland, Traupmann, \& Moy, 1973). Thus, if the position effects are due to strategic control processes, it should be possible to alter 
them by creating positional biases. That is, if mismatches are most probable in the right position, subjects should weight this position into the same-different decision relatively more than they do when mismatches are equally likely in all positions. Such positional biases should have less of an influence for the item task, because mismatches within any position do not ensure that the display should be classified as different.

\section{Method}

Subjects and Design. One hundred and forty-four subjects participated in a single session for Experiment 1, and 32 different subjects participated in two sessions for Experiment 2. They were students enrolled in introductory psychology courses at Auburn University, who received extra credit toward their course grades. In each experiment, type of matching rule (order, item) was varied between subjects and pair type (identical, rearranged, replacement) within subjects. Positional bias was a between-subjects factor in Experiment 1 and a within-subjects factor in Experiment 2.

Apparatus. Stimuli were presented in white on the dark display screen of a TRS-80 Model 4 microcomputer that had a P-4 phosphor decaying to $1 \%$ of its maximum intensity in $60 \mathrm{msec}$. The stimuli were composed of letters from the standard character set of the computer. Timing was controlled by the computer, with RTs recorded to the nearest millisecond.

Subjects responded by pressing one of two keys on the computer's keyboard. Half of the subjects in each condition responded "same" by pressing the " $Z$ " key (the leftmost key on the bottom row) with the left index finger and "different" by pressing the "?"' key (the rightmost key on the bottom row) with the right index finger. For the other half of the subjects, the assignments were reversed.

Stimuli. The stimuli were pairs of three-letter strings composed from uppercase versions of all consonants of the alphabet (excluding Y), with all letters being used approximately equally often. No letters were repeated within a string or between successive trials. The two strings in each pair were presented centered immediately above and immediately below an asterisk that served as a fixation point. From an approximate viewing distance of $50 \mathrm{~cm}$, the gap between the top and bottom strings was approximately $.80^{\circ}$. Each letter was $.23^{\circ}$ wide and $.57^{\circ} \mathrm{high}$, with a $.06^{\circ}$ separation between letters. Thus, each three-letter string was approximately $.81^{\circ}$ wide.

For Experiment 1, three different types of lists were constructed, with each list containing 360 pairs. The types of pairs employed can be indicated by using ABC to designate the first string, and then referring to the pair by using letters to reflect the relation of the second string to the first (this terminology was used by Angiolillo-Bent \& Rips, 1982, and by Proctor \& Healy, 1985, 1987). The lists were composed from three basic pair types: (1) identical pairs ( $A B C$ pairs); (2) rearranged pairs, for which the letters from the first string were permuted two (ACB, BAC) or four (BCA, CAB, and CBA) positions; and (3) replacement pairs based on the identical and rearranged pairs but with a letter replaced in the left, center, or right position (ABX, BXC, XBA, etc.).

Two hundred and seventy pairs in each list (90 identical, 90 rearranged, and 90 replacement) were test pairs, composed of the same letters in the same positions for the three lists. The only difference between the three lists was in the 90 additional filler items. These filler items were replacement pairs for all of the lists. In the neutral list, the position of replacement was distributed equally across the positions. However, for the left-bias list, 60 of the replacements were in the left position and 30 in the center position, whereas for the right-bias list, 60 were in the right position and 30 in the center position.

The use of lists with 90 identical, 90 rearranged, and 180 replacement pairs introduces a difference in response frequency between the two tasks. Only 90 of the pairs are correctly classified as same for the order task, whereas 180 of the pairs are thus classified for the item task. However, the difference in response frequency creates no problem for interpreting the results. By factorially manipulating task and response frequency, Proctor and Healy (1987) showed that response frequency does not influence the patterns of permutation and replacement effects that are obtained.

Every 12 consecutive trials in each list included 3 identical pairs, 3 rearranged pairs, 3 replacement pairs, and 3 filler replacement pairs. Every 5 consecutive rearranged pairs included 1 of each permutation, and every 18 consecutive replacement pairs included 1 of each permutation by position combination. The same restriction applied to the filler replacement pairs in the neutral list. Filler pairs that mismatched at the right position in the neutral list were altered to mismatch at the left position in the left-bias list; the opposite alteration was made for the right-bias list.

The lists were constructed similarly for Experiment 2, with the following exceptions. First, only left-bias and right-bias lists were used; second, for these lists, all of the 90 filler pairs mismatched in the left or right position, respectively.

Procedure. For the item task, subjects were instructed to respond "same" if the two strings contained the same letters, regardless of whether the order was the same. For the order task, subjects were told to respond "same" only if the two strings had the same letters in the same order. The instructions stressed that the subjects should respond rapidly, without making too many errors.

After the instructions, a practice block of 12 trials was presented, followed by a test list of 360 trials. For all subjects, the two strings in each pair were presented successively, with the following general procedure. The fixation asterisk occurred as a warning signal for $1 \mathrm{sec}$. Next, the string above fixation was presented for $500 \mathrm{msec}$, followed by a blank screen for $500 \mathrm{msec}$, and then the second string was presented until the subject responded. The RTs were measured from the onset of the second string. The fixation asterisk reappeared as a warning signal $500 \mathrm{msec}$ after the subject responded. There was a short rest after 180 trials.

In Experiment 1, each subject was tested with one of the three positional bias conditions in either the order or the item task. In Experiment 2, each subject was tested on separate days and performed the same task on both days, one day with the left positional bias and the other day with the right. The order of the positional bias conditions was counterbalanced across subjects. The withinsubject manipulation of positional bias was used in Experiment 2 to provide added power.

\section{Results}

Mean RTs for correct responses and percentages of errors $(P E s)$ were obtained for each subject as a function of pair type. So that the comparisons for the different positional biases are based on responses to the same letter strings, the filler items were excluded from analysis. For the primary data analyses, the identical, rearranged, and replacement pairs were analyzed separately. The means $(M \mathrm{~s})$ and $F$ ratios for Experiments 1 and 2 are designated by the subscripts 1 and 2, respectively. Except where noted, the RT and error data yielded consistent results (i.e., RT and PE were positively correlated). As a preview, the same pattern of results was found as in Proctor and Healy $(1985,1987)$, and there were no consistent effects of positional bias across the two experiments.

Identical pairs. The RTs to identical pairs (see Table 1) showed no significant effects in Experiment 1 or 2 . The only trends that approached significance were the main 
Table 1

Mean Reaction Times (in Miliseconds) and Percentages of Errors for the Identical Pairs in Experiments 1 and 2, as a Function of Task and Positional Bias (Left, Neutral, Right)

\begin{tabular}{|c|c|c|c|c|c|c|}
\hline \multirow[b]{3}{*}{ Task } & \multicolumn{6}{|c|}{ Positional Bias } \\
\hline & \multicolumn{3}{|c|}{ Experiment 1} & \multicolumn{3}{|c|}{ Experiment 2} \\
\hline & Left & Neutral & Right & Left & Neutral & Right \\
\hline \multicolumn{7}{|c|}{ Reaction Times } \\
\hline Order & 599 & 576 & 569 & 581 & - & 597 \\
\hline Item & 599 & 602 & 624 & 538 & - & 558 \\
\hline \multicolumn{7}{|c|}{ Percentage of Errors } \\
\hline Order & 8.8 & 9.0 & 8.7 & 11.7 & - & 12.1 \\
\hline Item & 5.1 & 5.8 & 6.0 & 4.7 & - & 4.4 \\
\hline
\end{tabular}

effect of task in Experiment $1\left[F_{1}(1,138)=2.10, p>\right.$ $.10]$ and the main effect of positional bias in Experiment 2 $\left[F_{2}(1,30)=2.50, p>.10\right]$.

For the error data (see Table 1), the task main effect was significant $\left[F_{1}(1,138)=11.4, p=.001 ; F_{2}(1,30)=\right.$ $4.50, p<.05]$, with the other two terms exhibiting no systematic trend. Subjects made more errors in the order task $\left(P E_{1}=8.8 ; P E_{2}=11.9\right)$ than in the item task $\left(P E_{1}=5.6 ; P E_{2}=4.6\right)$. Of most interest, the positional bias manipulation had no significant effect.

Rearranged pairs. The RTs to the rearranged pairs (see Table 2) showed main effects of task $\left[F_{1}(1,138)=94.2\right.$, $p<.001 ; F_{2}(1,30)=4.50, p<.05$ ] and permutation $\left[F_{1}(4,552)=5.34, p<.001 ; F_{2}(4,120)=4.01, p<.01\right]$, as well as an interaction of the two variables $\left[F_{1}(4,552)=\right.$ $\left.105.1, p<.001 ; F_{2}(4,120)=47.8, p<.001\right]$. Responses were faster in the order task $\left(M_{1}=587 \mathrm{msec} ; M_{2}=\right.$ $605 \mathrm{msec})$ than in the item task $\left(M_{1}=863 \mathrm{msec}\right.$; $M_{2}=749 \mathrm{msec}$ ). The interaction indicates that the permutation effect was opposite for the two tasks, as in previous studies (Proctor \& Healy, 1985, 1987). For the order task, RTs decreased as the number of permuted positions increased $\left(M_{1}=659 \mathrm{msec}\right.$ and $M_{2}=674 \mathrm{msec}$ for permutations of two positions; $M_{1}=538 \mathrm{msec}$ and $M_{2}=$ $559 \mathrm{msec}$ for permutations of four positions), whereas for the item task, RTs increased $\left(M_{1}=814 \mathrm{msec}\right.$ and $M_{2}=$ $710 \mathrm{msec}$ for permutations of two positions; $M_{1}=$ $896 \mathrm{msec}$ and $M_{2}=776 \mathrm{msec}$ for permutations of four positions). The main effect for permutation reflects the fact that the permutation effect was somewhat greater for the order task than for the item task; thus, the opposing effects for the two tasks did not cancel completely.

The error data (see Table 2) showed similar effects of task $\left[F_{1}(1,138)=58.4, p<.001 ; F_{2}(1,30)=8.43\right.$, $p<.01]$, permutation $\left[F_{1}(4,552)=27.8, p<.001\right.$; $\left.F_{2}(4,120)=8.41, p<.001\right]$, and task $\times$ permutation $\left[F_{1}(4,552)=53.9, p<.001 ; F_{2}(4,120)=24.7, p<\right.$ $.001]$. Consistent with the RT data, responses were less accurate for the item task $\left(P E_{1}=13.27 ; P E_{2}=13.38\right)$ than for the order task $\left(P E_{1}=5.85 ; P E_{2}=7.87\right)$, and the two tasks showed opposing permutation effects. For the order task, the percentage of errors decreased as the number of permuted positions increased $\left(P E_{1}=10.0\right.$ and
$P E_{2}=14.4$ for permutations of two positions; $P E_{1}=3.09$ and $P E_{2}=3.6$ for permutations of four positions). This relation was reversed for the item task $\left(P E_{1}=9.8\right.$ and $P E_{2}=9.0$ for permutations of two positions; $P E_{1}=15.6$ and $P E_{2}=16.3$ for permutations of four positions). As with the RT data, the permutation effect was somewhat greater for the order task than for the item task.

In Experiment 1, the error data also showed a significant positional bias effect $\left[F_{1}(2,138)=3.80, p<.03\right]$ and a tendency toward a positional bias $\times$ task interaction $\left[F_{2}(2,138)=2.33, p=.10\right]$. The positional bias effect is that fewer errors were made when there was a neutral bias $\left(P E_{1}=8.22\right)$ than when there was a left $\left(P E_{1}=9.08\right)$ or right $\left(P E_{1}=11.4\right)$ bias. The trend toward an interaction with task occurred because the increase in errors when subjects were biased toward the right position was greater for the item task (right bias - neutral $=5.5 \%$ ) than for the order task (right bias - neutral $=0.8 \%$ ). In Experiment 2, the positional bias $\times$ permutation interaction was significant $\left[F_{2}(4,120)=2.83, p<.03\right]$. This interaction reflects the fact that the percentage of errors was greater for ACB pairs when the bias was toward the right position $\left(P E_{2}=17.9\right)$ than when it was toward the left $\left(P E_{2}=12.4\right)$, whereas accuracy across the remaining pairs was slightly worse when the bias was toward the left position $\left(P E_{2}=10.0\right)$ rather than toward the right $\left(P E_{2}=9.0\right)$.

Table 2

Mean Reaction Times (in Milliseconds) and Percentages of Errors for the Rearranged Pairs in Experiments 1 and 2, as a Function of Task, Permutation, and Positional Bias (Left, Neutral, Right)

\begin{tabular}{|c|c|c|c|c|c|c|}
\hline \multirow{3}{*}{$\begin{array}{c}\text { Task and } \\
\text { Permutation }\end{array}$} & \multicolumn{6}{|c|}{ Positional Bias } \\
\hline & \multicolumn{3}{|c|}{ Experiment 1} & \multicolumn{3}{|c|}{ Experiment 2} \\
\hline & Left & Neutral & Right & Left & Neutral & Right \\
\hline
\end{tabular}

Reaction Times

\begin{tabular}{ccccccc} 
Order & \multicolumn{7}{c}{ Reaction Times } \\
ACB & 739 & 707 & 694 & 729 & - & 736 \\
BAC & 617 & 610 & 589 & 613 & - & 619 \\
BCA & 564 & 542 & 532 & 568 & - & 541 \\
CAB & 541 & 544 & 515 & 578 & - & 562 \\
CBA & 541 & 536 & 529 & 552 & - & 550 \\
Item & & & & & & \\
ACB & 750 & 805 & 779 & 653 & - & 689 \\
BAC & 836 & 877 & 833 & 764 & - & 734 \\
BCA & 872 & 935 & 929 & 810 & - & 793 \\
CAB & 893 & 913 & 882 & 764 & - & 776 \\
CBA & 854 & 881 & 908 & 770 & - & 740
\end{tabular}

Percentage of Errors

\begin{tabular}{crrrrrr} 
Order & \multicolumn{7}{c}{ PCB } & 17.8 & 12.9 & 18.1 & 17.4 & - & 27.4 \\
BAC & 3.5 & 4.4 & 3.2 & 7.7 & - & 4.9 \\
BCA & 6.3 & 6.5 & 6.0 & 7.3 & - & 6.6 \\
CAB & 0.7 & 1.6 & 2.6 & 2.1 & - & 2.8 \\
CBA & 1.6 & 1.4 & 1.2 & 1.1 & - & 1.4 \\
Item & & & & & & \\
ACB & 6.5 & 7.2 & 13.9 & 7.3 & - & 8.3 \\
BAC & 10.9 & 7.4 & 12.9 & 9.7 & - & 10.8 \\
BCA & 17.4 & 19.4 & 22.7 & 22.6 & - & 18.1 \\
CAB & 13.9 & 12.3 & 17.4 & 15.3 & - & 12.2 \\
CBA & 12.3 & 9.1 & 16.0 & 14.2 & - & 15.3 \\
\hline
\end{tabular}


Two findings from the RT and error data are important to note. First, positional bias had no effect on the RTs to rearranged pairs and inconsistent effects on errors across the two experiments, with no interaction involving positional bias and task attaining statistical significance. Second, there was evidence for a greater difference in the weightings of the left and right positions in the order task relative to the item task. For the permutations with displacement counts of two, the difference between the ACB and BAC permutations was greater for the order task than for the item task on PEs [12.6\% versus $1.2 \%$ for Experiment 1 and $16.1 \%$ versus $2.5 \%$ for Experiment $2 ; F_{1}(1,138)=31.4$, and $F_{2}(1,30)=15.5$, ps $<.001]$, with the RT data showing similar trends [108 versus $71 \mathrm{msec}$ for Experiment 1 and 117 versus $78 \mathrm{msec}$ for Experiment 2; $F_{1}(1,138)=4.28, p<.05$, and $\left.F_{2}(1,30)=1.53, p<.25\right]$. Thus, a match in the leftmost position creates relative difficulty for correctly classifying these pairs as different in the order task. The distinct serial-position effects for the two tasks replicate the findings of Proctor and Healy $(1985,1987)$.

Replacement pairs. For RTs (see Tables 3 and 4), the main effects of task $\left[F_{1}(1,138)=165.5, p<.001\right.$;
$\left.F_{2}(1,30)=14.4, p<.001\right]$, base permutation $\left[F_{1}(5,690)\right.$ $\left.=9.57, p<.001 ; F_{2}(5,150)=5.06, p<.001\right]$, and replacement position $\left[F_{1}(2,276)=38.5, p<.001 ; F_{2}(2,60)\right.$ $=9.57, p<.001]$ were significant. Responses were faster with the order task $\left(M_{1}=525 \mathrm{msec} ; M_{2}=521 \mathrm{msec}\right)$ than with the item task $\left(M_{1}=822 \mathrm{msec} ; M_{2}=729 \mathrm{msec}\right)$, and faster when the replacement position was the center $\left(M_{1}=647 \mathrm{msec} ; M_{2}=606 \mathrm{msec}\right)$ then when it was the left $\left(M_{1}=668 \mathrm{msec} ; M_{2}=633 \mathrm{msec}\right)$ or right $\left(M_{1}=\right.$ $691 \mathrm{msec} ; M_{2}=636 \mathrm{msec}$ ). Across the two experiments, the CBA base permutation yielded the fastest RTs $(M=$ $630 \mathrm{msec}$ ), and the BAC permutation yielded the slowest $(M=676 \mathrm{msec})$, with the others intermediate (ABC, $M=$ $659 \mathrm{msec}$; ACB, $M=649 \mathrm{msec}$; CAB, $M=638 \mathrm{msec}$ ).

In addition, several two-way interactions were significant. The interaction of task $\times$ replacement position $\left[F_{1}(2,276)=35.1, p<.001 ; F_{2}(2,60)=4.28, p<.02\right]$ indicates that the U-shaped function for replacement position was apparent for the item task (left to right, $M s=855,768$, and $844 \mathrm{msec}$ in Experiment 1 and 739, 699, and $741 \mathrm{msec}$ in Experiment 2) but not for the order task (left to right, $M \mathrm{~s}=522,526,538 \mathrm{msec}$ in Experiment 1 and 518, 513, and $531 \mathrm{msec}$ in Experiment 2).

Table 3

Mean Reaction Times (in Milliseconds) and Percentages of Errors for the Replacement Pairs in Experiment 1, as a Function of Task, Permutation, Positional Bias (Lef, Neutral, Right), and Replacement Position (Left, Center, Right)

\begin{tabular}{|c|c|c|c|c|c|c|c|c|c|}
\hline \multirow{3}{*}{$\begin{array}{l}\text { Task and } \\
\text { Permutation }\end{array}$} & \multicolumn{9}{|c|}{ Replacement Position } \\
\hline & \multicolumn{3}{|c|}{ Left Bias } & \multicolumn{3}{|c|}{ Neutral Bias } & \multicolumn{3}{|c|}{ Right Bias } \\
\hline & Left & Center & Right & Left & Center & Right & Left & Center & Right \\
\hline \multicolumn{10}{|c|}{ Reaction Times } \\
\hline \multicolumn{10}{|l|}{ Order } \\
\hline $\mathrm{ABC}$ & 554 & 588 & 680 & 508 & 526 & 576 & 501 & 557 & 597 \\
\hline $\mathrm{ACB}$ & 535 & 569 & 580 & 544 & 530 & 543 & 495 & 492 & 536 \\
\hline BAC & 553 & 564 & 528 & 527 & 522 & 500 & 534 & 553 & 485 \\
\hline BCA & 548 & 500 & 541 & 498 & 519 & 521 & 493 & 487 & 507 \\
\hline $\mathrm{CAB}$ & 525 & 548 & 527 & 500 & 528 & 518 & 536 & 511 & 473 \\
\hline CBA & 526 & 512 & 537 & 528 & 481 & 515 & 484 & 481 & 517 \\
\hline \multicolumn{10}{|l|}{ Item } \\
\hline $\mathrm{ABC}$ & 780 & 746 & 800 & 801 & 745 & 785 & 791 & 778 & 797 \\
\hline $\mathrm{ACB}$ & 887 & 787 & 817 & 842 & 785 & 777 & 868 & 783 & 770 \\
\hline BAC & 1048 & 795 & 853 & 923 & 801 & 898 & 951 & 817 & 882 \\
\hline BCA & 821 & 779 & 892 & 830 & 832 & 845 & 803 & 789 & 855 \\
\hline $\mathrm{CAB}$ & 844 & 770 & 866 & 825 & 794 & 911 & 798 & 752 & 879 \\
\hline CBA & 808 & 712 & 844 & 892 & 670 & 918 & 878 & 685 & 794 \\
\hline \multicolumn{10}{|c|}{ Percentage of Errors } \\
\hline Order & & & & & & & & & \\
\hline $\mathrm{ABC}$ & 0.8 & 3.4 & 6.6 & 3.4 & 5.8 & 10.8 & 0.8 & 2.6 & 6.6 \\
\hline $\mathrm{ACB}$ & 0.8 & 2.6 & 3.4 & 0.0 & 0.0 & 1.6 & 1.6 & 0.0 & 0.8 \\
\hline BAC & 1.6 & 0.0 & 0.0 & 4.2 & 2.6 & 0.8 & 0.8 & 3.4 & 0.8 \\
\hline $\mathrm{BCA}$ & 4.2 & 0.0 & 0.0 & 0.0 & 0.8 & 0.0 & 0.8 & 0.8 & 1.6 \\
\hline $\mathrm{CAB}$ & 2.6 & 0.8 & 2.6 & 1.6 & 0.8 & 0.8 & 1.6 & 0.0 & 0.0 \\
\hline $\mathrm{CBA}$ & 1.6 & 2.6 & 0.8 & 0.8 & 0.8 & 0.0 & 0.0 & 0.0 & 0.0 \\
\hline \multicolumn{10}{|l|}{ Item } \\
\hline $\mathrm{ABC}$ & 5.0 & 10.0 & 7.6 & 11.6 & 5.8 & 10.0 & 13.4 & 8.4 & 6.6 \\
\hline $\mathrm{ACB}$ & 9.0 & 8.4 & 7.6 & 10.8 & 2.6 & 4.2 & 17.6 & 6.6 & 5.8 \\
\hline BAC & 18.4 & 5.0 & 9.2 & 14.2 & 4.2 & 11.6 & 14.2 & 5.0 & 3.4 \\
\hline BCA & 9.2 & 6.6 & 7.6 & 4.2 & 6.6 & 7.6 & 6.6 & 8.4 & 6.6 \\
\hline $\mathrm{CAB}$ & 6.6 & 5.0 & 8.4 & 5.8 & 2.6 & 5.0 & 7.6 & 4.2 & 9.2 \\
\hline CBA & 8.4 & 2.6 & 6.6 & 3.4 & 0.8 & 6.6 & 8.4 & 1.6 & 8.4 \\
\hline
\end{tabular}


Table 4

Mean Reaction Times (in Milliseconds) and Percentages of Errors for the Replacement Pairs in Experiment 2, as a Function of Task, Permutation, Positional Bias (Left, Right), and Replacement Position (Left, Center, Right)

\begin{tabular}{|c|c|c|c|c|c|c|}
\hline \multirow{3}{*}{$\begin{array}{c}\text { Task and } \\
\text { Permutation }\end{array}$} & \multicolumn{6}{|c|}{ Replacement Position } \\
\hline & \multicolumn{3}{|c|}{ Left Bias } & \multicolumn{3}{|c|}{ Right Bias } \\
\hline & Left & Center & Right & Left & Center & Right \\
\hline \multicolumn{7}{|c|}{ Reaction Times } \\
\hline \multicolumn{7}{|l|}{ Order } \\
\hline$A B C$ & 522 & 583 & 670 & 537 & 563 & 589 \\
\hline $\mathrm{ACB}$ & 511 & 518 & 552 & 525 & 520 & 563 \\
\hline BAC & 543 & 499 & 465 & 563 & 535 & 488 \\
\hline $\mathrm{BCA}$ & 515 & 493 & 518 & 501 & 457 & 539 \\
\hline CAB & 514 & 501 & 477 & 491 & 497 & 477 \\
\hline CBA & 508 & 496 & 490 & 482 & 491 & 535 \\
\hline \multicolumn{7}{|l|}{ Item } \\
\hline $\mathrm{ABC}$ & 684 & 691 & 733 & 745 & 730 & 676 \\
\hline ACB & 688 & 692 & 702 & 767 & 671 & 754 \\
\hline $\mathrm{BAC}$ & 857 & 693 & 767 & 895 & 731 & 696 \\
\hline $\mathrm{BCA}$ & 695 & 773 & 739 & 731 & 733 & 778 \\
\hline CAB & 726 & 677 & 799 & 716 & 677 & 791 \\
\hline CBA & 739 & 661 & 689 & 725 & 661 & 769 \\
\hline \multicolumn{7}{|c|}{ Percentage of Errors } \\
\hline \multicolumn{7}{|l|}{ Order } \\
\hline ABC & 1.3 & 3.8 & 6.3 & 0.0 & 6.3 & 13.8 \\
\hline $\mathrm{ACB}$ & 0.0 & 2.5 & 0.0 & 1.3 & 0.0 & 2.5 \\
\hline BAC & 2.5 & 1.3 & 1.3 & 1.3 & 1.3 & 2.5 \\
\hline BCA & 2.5 & 1.3 & 3.8 & 2.5 & 0.0 & 2.5 \\
\hline CAB & 2.5 & 2.5 & 1.3 & 1.3 & 1.3 & 1.3 \\
\hline CBA & 2.5 & 2.5 & 1.3 & 1.3 & 1.3 & 0.0 \\
\hline \multicolumn{7}{|l|}{ Item } \\
\hline $\mathrm{ABC}$ & 3.8 & 5.0 & 12.5 & 11.3 & 6.3 & 7.5 \\
\hline $\mathrm{ACB}$ & 8.8 & 5.0 & 6.3 & 15.0 & 5.0 & 5.0 \\
\hline BAC & 20.0 & 3.8 & 8.8 & 16.3 & 5.0 & 8.8 \\
\hline $\mathrm{BCA}$ & 8.8 & 8.8 & 7.5 & 7.5 & 7.5 & 8.8 \\
\hline CAB & 6.3 & 3.8 & 6.3 & 10.0 & 7.5 & 11.3 \\
\hline CBA & 6.3 & 1.3 & 3.8 & 3.8 & 3.8 & 3.8 \\
\hline
\end{tabular}

The interaction of task $\times$ base permutation $\left[F_{1}(5,690)=\right.$ $\left.17.4, p<.001 ; F_{2}(5,150)=9.99, p<.001\right]$ was also significant. The BAC base permutation had the longest RTs for the item task (Ms of 780, 813, 885, 827, 826, and $800 \mathrm{msec}$ for the $\mathrm{ABC}, \mathrm{ACB}, \mathrm{BAC}, \mathrm{BCA}, \mathrm{CAB}$, and CBA permutations, respectively, in Experiment 1; the corresponding means in Experiment 2 were 710, 713, $773,742,714$, and $707 \mathrm{msec}$ ). In contrast, the ABC permutation had the longest RTs for the order task (Ms= $565,536,529,513,518$, and $509 \mathrm{msec}$ for the ABC, ACB, BAC, BCA, CAB, and CBA permutations, respectively, in Experiment 1; the corresponding means in Experiment 2 were 578, 532, 516, 504, 493, and $501 \mathrm{msec}$ ).

The replacement position $\times$ base permutation interaction also was significant $\left[F_{1}(10,1380)=8.11, p<.001\right.$; $\left.F_{2}(10,300)=6.35, p<.001\right]$. The individual base permuations differed in the magnitude of the replacement-position effect as well as in whether the slowest responses occurred when the replacement was in the left position (BAC permutation), the right position (ABC, $B C A$, and $C A B$ permutations), or either the left or the right position (ACB and CBA permutations). In Experiment 1, the three-way interaction of these variables with task was significant as well $\left[F_{1}(10,1380)=7.19, p<.001\right]$.

The error data (see Tables 3 and 4) showed main effects of task $\left[F_{1}(1,138)=73.6, p<.001 ; F_{2}(1,30)=\right.$ $22.1, p<.001]$, base permutation $\left[F_{1}(5,690)=9.46\right.$, $\left.p<.001 ; F_{2}(5,150)=4.83, p<.001\right]$, and replacement position $\left[F_{1}(2,276)=13.8, p<.001 ; F_{2}(2,60)=9.30\right.$, $p<.001]$. Fewer errors were made in the order task $\left(P E_{1}\right.$ $\left.=1.7 ; P E_{2}=2.2\right)$ than in the item task $\left(P E_{1}=7.4\right.$; $P E_{2}=7.6$ ); the percentage of errors showed a U-shaped function of replacement position (left to right, $P E s=5.6$, 3.4, and 4.7 in Experiment 1, and 5.8, 3.7, and 5.4 in Experiment 2) similar to that shown for RTs; and the most errors were made to base permutations of the $\mathrm{ABC}$ type $\left(P E_{1}=6.6 ; P E_{2}=6.6\right)$ and the least to permutations of the CBA type $\left(P E_{1}=2.9 ; P E_{2}=3.8\right)$, with the other permutations intermediate (ACB, $P E_{1}=4.7$ and $P E_{2}=$ 4.3; $\mathrm{BAC}, P E_{1}=5.6$ and $P E_{2}=6.1 ; \mathrm{BCA}, P E_{1}=4.0$ and $P E_{2}=5.2 ; \mathrm{CAB}, P E_{1}=6.0$ and $P E_{2}=4.7$ ).

Additionally, several two-way interactions were significant for the error data. The task $\times$ replacement position interaction $\left[F_{1}(2,276)=13.6, p<.001 ; F_{2}(2,60)=12.9\right.$, $p<.001]$ indicates that the U-shaped position function was evident for the item task but not for the order task (left to right, for the order task, $P E \mathrm{~s}=1.5,1.5$, and 2.1 in Experiment 1 and 1.6, 2.0, and 3.1 in Experiment 2; for the item task, $P E s=9.7,5.3$, and 7.3 in Experiment 1 and 9.9, 5.4, and 7.6 in Experiment 2). Hence, there was more left-to-right weighting in the order task than in the item task, as it was for the RT data in the present study and as was found previously (Proctor \& Healy, 1985, 1987).

The interactions of base permutation with task $\left[F_{1}(5,690)\right.$ $\left.=2.89, p<.025 ; F_{2}(5,150)=3.92, p<.005\right]$ and with replacement position $\left[F_{1}(10,1380)=3.26, p<.001\right.$; $\left.F_{2}(10,300)=2.42, p<.05\right]$ are consistent with the similar interactions obtained for RTs. In Experiment 1, the three-way interaction of these variables $\left[F_{1}(10,1380)\right.$ $=4.24, p<.001]$ also was significant, as it also was for RTs.

Importantly, no terms involving positional bias were significant for either the RTs or the PEs. Thus, responses to the replacement pairs were not affected reliably by the different probabilities for mismatches within the respective positions.

\section{Discussion}

The results obtained in Experiments 1 and 2 replicate closely those reported by Proctor and Healy $(1985,1987)$. The order and item effects showed approximately mirrorimage effects of displacement. Moreover, the order task showed a greater left-to-right weighting of positions for both the rearranged and the replacement pairs than did the item task.

The most important outcome is that positional bias had little effect on the patterns of results for either the order or the item task. In both experiments, the only effect of positional bias was on the errors to rearranged pairs, and 
the specific pattern for this effect was different across the two experiments. Otherwise, positional bias had no reliable effect. Thus, the results of Experiments 1 and 2 show little evidence that subjects are able to control the relative weightings given to the within-position comparisons. Consequently, they do not support the hypothesis that the distinct serial-position functions for the order and item tasks reflect controllable differences in strategy.

\section{EXPERIMENTS 3 AND 4}

Experiments 1 and 2 demonstrated that the weightings of within-position comparisons are not affected by positional biases. This outcome suggests that subjects cannot choose to weight selectively particular within-position comparisons. Perhaps the inability to weight preferentially any specific position is due to the fact that comparisons within all three positions are pertinent to the decision for both the order and the item tasks. In contrast, betweenposition comparisons are pertinent to the same-different decision only for the item task. Consequently, in the order task such comparisons should be avoided if possible.

If subjects have some control over the weights given to between-position comparisons, then making these comparisons more difficult should encourage subjects to avoid performing them in the order task. In Experiments 1 and 2 , as well as in the previous experiments by Proctor and Healy $(1985,1987)$, the letters within each string were displayed in adjacent positions on the computer screen and thus were minimally separated from each other. If the proximity of the letters in Experiments 1 and 2 produced automatic (uncontrolled) between-position comparisons, then increasing the distance between the letters may discourage such comparisons when they are irrelevant, as in the order task. Conversely, because such comparisons are necessary in the item task, increased interletter distance should not change the pattern of effects.

Experiment 3 included such a manipulation of the spacing between the letters within each string (e.g., Eriksen \& Eriksen, 1979; Shaw, 1969) to minimize the possibility of automatic between-position comparisons and to increase the difficulty of performing controlled between-position comparisons. Experiment 4 filled the spaces between the letters with extraneous asterisk characters (see Healy, Conboy, \& Drewnowski, 1987) so that any betweenposition comparisons would have to be extremely selective and thus highly unlikely if they were under control. If the between-position comparisons in the order task are still evident under these conditions, then that would suggest that subjects are unable to control these comparisons.

\section{Method}

Subjects and Design. Sixty-four students participated in Experiment 3, and 64 different subjects participated in Experiment 4. All were students enrolled in introductory psychology courses at the University of Colorado, who were satisfying a course requirement. In each experiment, type of matching rule (order, item) and spacing condition were varied between subjects.
Apparatus. The stimuli were presented on the display screen of a Visual Technology Visual 200 CRT terminal, which uses a P-4 phosphor. Timing was controlled by a Digital PDP-11/03-L minicomputer with a programmable real-time clock. Subjects responded by pressing one of two response buttons that were mounted on a board. Half of the subjects in each condition indicated "same" by pressing the left-hand button and "different" by pressing the righthand button. For the other half of the subjects, the pairing was reversed.

Stimuli and Procedure. The stimuli were three-letter strings, presented as in Experiments 1 and 2. From a viewing distance of approximately $50 \mathrm{~cm}$, the separation between the top and bottom strings was $.74^{\circ}$. Each letter was $.23^{\circ}$ wide and $.46^{\circ}$ high; the separation between adjacent letters was $.04^{\circ}$.

The same sets of three-letter strings were used as in Experiments 1 and 2 , with the exception that the 90 filler items were those used by Proctor and Healy (1987, Experiment 2). For the order task, these filler items were identical pairs; for the item task, the items were replacement pairs (with the position of difference distributed equally across positions). This method allows the percentage of same and different pairs to be $50 \%$ for both tasks. The procedure was similar to that of Experiments 1 and 2, with the exception that the trials were divided into four blocks of 90 each, with a short rest at the end of each block.

In Experiment 3, four groups of subjects were tested with either the order task or the item task, and with the three letters in each string presented adjacent to each other or each separated by two blank character spaces of approximately $.54^{\circ}$ total. In focusedattention tasks for which a target is flanked by distractors, changes in separation in this range produce a large decrease in the effect of the distractors on target identification (see, e.g., Eriksen \& Eriksen, 1979). In Experiment 4, the letters were always separated, and the intervening spaces were either blank or filled with asterisk characters.

\section{Results}

The data, which were analyzed similarly to those from Experiments 1 and 2, yielded comparable results. Spacing had no effect, and filling the spaces with asterisks increased the effect of displacement, but it did so similarly for both the order and the item tasks. The statistics for Experiments 3 and 4 are designated by the subscripts 3 and 4 , respectively.

Identical pairs. The RT data (see Table 5) showed only a main effect for task $\left[F_{3}(1,60)=5.00, p<.03\right.$; $\left.F_{4}(1,60)=3.90, p=.05\right]$. Responses were faster for the order task $\left(M_{3}=561 \mathrm{msec} ; M_{4}=589 \mathrm{msec}\right)$ than for

Table 5

Mean Reaction Times (in Milliseconds) and Percentages of Errors for the Identical Pairs in Experiments 3 and 4, as a Function of Task and Spacing Condition (No Space, Space, Filled)

\begin{tabular}{|c|c|c|c|c|}
\hline \multirow[b]{3}{*}{ Task } & \multicolumn{4}{|c|}{ Spacing Condition } \\
\hline & \multicolumn{2}{|c|}{ Experiment 3} & \multicolumn{2}{|c|}{ Experiment 4} \\
\hline & No Space & Space & Space & Filled \\
\hline \multicolumn{5}{|c|}{ Reaction Times } \\
\hline $\begin{array}{l}\text { Order } \\
\text { Item }\end{array}$ & $\begin{array}{l}582 \\
623\end{array}$ & $\begin{array}{l}539 \\
608\end{array}$ & $\begin{array}{l}575 \\
634\end{array}$ & $\begin{array}{l}602 \\
658\end{array}$ \\
\hline \multicolumn{5}{|c|}{ Percentage of Errors } \\
\hline $\begin{array}{l}\text { Order } \\
\text { Item }\end{array}$ & $\begin{array}{l}3.9 \\
2.6 \\
\end{array}$ & $\begin{array}{l}4.4 \\
3.2 \\
\end{array}$ & $\begin{array}{l}3.3 \\
3.8 \\
\end{array}$ & $\begin{array}{l}3.8 \\
2.8 \\
\end{array}$ \\
\hline
\end{tabular}


the item task $\left(M_{3}=616 \mathrm{msec} ; M_{4}=646 \mathrm{msec}\right)$. The error data showed no significant effects, with only a nonsignificant trend toward a task main effect in Experiment 3 $\left[F_{3}(1,60)=3.02, p<.10\right]$. In that experiment, responses tended to be more accurate for the item task $\left(P E_{3}=2.9\right)$ than for the order task $\left(P E_{3}=4.2\right)$.

Rearranged pairs. For RTs (see Table 6), a main effect of task $\left[F_{3}(1,60)=36.6, p<.001 ; F_{4}(1,60)=45.1\right.$, $p<.001]$ was obtained. Responses were faster for the order task $\left(M_{3}=644 \mathrm{msec} ; M_{4}=654 \mathrm{msec}\right)$ than for the item task $\left(M_{3}=854 \mathrm{msec} ; M_{4}=925 \mathrm{msec}\right)$. In addition, the two-way interaction of task $\times$ permutation was significant $\left[F_{3}(4,240)=38.6, p<.001 ; F_{4}(4,240)=\right.$ $42.4, p<.001]$. The RTs decreased with increasing displacement for the order task $\left(M_{3}=700 \mathrm{msec}\right.$ and $M_{4}=$ $706 \mathrm{msec}$ for permutations of two positions; $M_{3}=607 \mathrm{msec}$ and $M_{4}=619 \mathrm{msec}$ for permutations of four positions), but increased for the item task $\left(M_{3}=\right.$ $829 \mathrm{msec}$ and $M_{4}=862 \mathrm{msec}$ for permutations of two positions; $M_{3}=934 \mathrm{msec}$ and $M_{4}=967 \mathrm{msec}$ for permutations of four positions), as in Experiments 1 and 2.

In Experiment 4, the three-way interaction of task and permutation with the space/filled variable was significant $\left[F_{4}(4,240)=3.44, p<.01\right]$. This interaction is due to the accentuation of the displacement effects when the asterisks filled the spaces between letters relative to when

Table 6

Mean Reaction Times (in Milliseconds) and Percentages of Errors for the Rearranged Pairs in Experiments 3 and 4, as a Function of Task, Permutation, and Spacing Condition (No Space, Space, Filled)

\begin{tabular}{ccccc}
\hline & \multicolumn{3}{c}{ Spacing Condition } \\
\cline { 2 - 3 } Task and & \multicolumn{2}{c}{ Experiment 3} & \multicolumn{2}{c}{ Experiment 4} \\
\cline { 2 - 3 } \cline { 5 - 5 } Permutation & No Space & Space & Space & Filled \\
\hline \multicolumn{5}{c}{ Reaction Times } \\
Order & \multicolumn{3}{c}{} \\
ACB & 782 & 704 & 715 & 783 \\
BAC & 676 & 637 & 627 & 698 \\
BCA & 633 & 605 & 613 & 641 \\
CAB & 637 & 559 & 594 & 627 \\
CBA & 615 & 592 & 610 & 630 \\
Item & & & & \\
ACB & 810 & 766 & 858 & 816 \\
BAC & 923 & 815 & 908 & 866 \\
BCA & 1002 & 911 & 941 & 998 \\
CAB & 945 & 874 & 960 & 996 \\
CBA & 990 & 881 & 949 & 958 \\
& & & & \\
Order & & Percentage of Errors & & \\
ACB & 17.4 & 16.3 & 14.6 & 17.0 \\
BAC & 4.5 & 5.6 & 5.9 & 9.7 \\
BCA & 3.8 & 2.1 & 3.1 & 1.7 \\
CAB & 2.1 & 3.5 & 3.1 & 2.8 \\
CBA & 1.0 & 2.1 & 1.7 & 2.8 \\
Item & & & & \\
ACB & 6.3 & 6.3 & 10.2 & 4.9 \\
BAC & 8.7 & 7.3 & 12.2 & 6.9 \\
BCA & 13.5 & 12.8 & 15.9 & 15.6 \\
CAB & 12.5 & 10.4 & 16.3 & 13.2 \\
CBA & 10.8 & 12.5 & 17.0 & 15.6 \\
\hline
\end{tabular}

they did not (the means for permutations with displacement counts of two and four, respectively, were 671 and $606 \mathrm{msec}$ for the order task, spaced condition; 741 and $633 \mathrm{msec}$ for the order task, filled condition; 883 and $950 \mathrm{msec}$ for the item task, spaced condition; and 841 and $984 \mathrm{msec}$ for the item task, filled condition).

For errors, the task main effect $\left[F_{3}(1,60)=11.9, p<\right.$ $\left..01 ; F_{4}(1,60)=15.9, p<.001\right]$ and the task $\times$ permutation interaction $\left[F_{3}(4,240)=27.2, p<.001\right.$; $\left.F_{4}(4,240)=26.2, p<.001\right]$ were significant. More errors were made for the item task $\left(P E_{3}=10.1 ; P E_{4}=\right.$ 12.8) than for the order task $\left(P E_{3}=5.8 ; P E_{4}=6.2\right)$. Also, the percentage of errors was an increasing function of displacement for the item task $\left(P E_{3}=7.2\right.$ and $P E_{4}=8.6$ for permutations of two positions; $P E_{3}=12.1$ and $P E_{4}=15.6$ for permutations of four positions), but a decreasing function for the order task $\left(P E_{3}=11.0\right.$ and $P E_{4}=11.8$ for permutations of two positions; $P E_{3}=2.4$ and $P E_{4}=2.5$ for permutations of four positions), as in Experiments 1 and 2 . The main effect of permutation also was significant in Experiment $3\left[F_{3}(4,240)=6.12, p<\right.$ $.001]$. This effect was due primarily to the greater error rate for the ACB pairs $\left(P E_{3}=11.6\right)$ than for the other permutations $\left(P E_{3}=7.0\right)$.

As in Experiments 1 and 2, evidence for a greater leftto-right weighting of positions in the order task was apparent from the permutations with displacement counts of two. The difference between the ACB and BAC permutations was larger in the order task than in the item task for both RTs and PEs (86 vs. $81 \mathrm{msec}$ and $11.8 \%$ vs. $1.7 \%$ for Experiment 3, and 86 vs. $55 \mathrm{msec}$ and $8.0 \%$ vs. $2.0 \%$ for Experiment 4 ).

Replacement pairs. The RT data (see Tables 7 and 8) showed main effects of task $\left[F_{3}(1,60)=44.3, p<.001\right.$; $\left.F_{4}(1,60)=50.2, p<.001\right]$ and base permutation $\left[F_{3}(5,300)=8.09, p<.001 ; F_{4}(5,300)=10.7, p<\right.$ $.001]$ as well as a task $\times$ permutation interaction $\left[F_{3}(5,300)=11.3, p<.001 ; F_{4}(5,300)=10.6, p<\right.$ .0011 . Mean RTs were faster for the order task $\left(M_{3}=\right.$ $\left.596 \mathrm{msec} ; M_{4}=619 \mathrm{msec}\right)$ than for the item task $\left(M_{3}=\right.$ $826 \mathrm{msec} ; M_{4}=854 \mathrm{msec}$ ) and decreased as the number of displaced positions for the base permutation increased, with the specific pattern of the latter effect differing somewhat across the two tasks).

Also, the main effect of replacement position was significant $\left[F_{3}(2,120)=16.7, p<.001 ; F_{4}(2,120)=31.4\right.$, $p<.001]$, with responses being faster when the replaced letter was in the center position $\left(M_{3}=681 \mathrm{msec} ; M_{4}=\right.$ $703 \mathrm{msec})$ than when it was in the left $\left(M_{3}=720 \mathrm{msec}\right.$; $\left.M_{4}=741 \mathrm{msec}\right)$ or right $\left(M_{3}=732 \mathrm{msec} ; M_{4}=\right.$ $766 \mathrm{msec}$ ) positions. The two-way interaction of replacement position with task $\left[F_{3}(2,120)=13.6, p<.001\right.$; $\left.F_{4}(2,120)=13.6, p<.001\right]$ was again significant, indicating that the U-shaped pattern for position of replacement was apparent only for the item task (in Experiment 3, Ms $=860,774$, and $844 \mathrm{msec}$, for the left, center, and right positions in the item task, and 579, 588, and $621 \mathrm{msec}$ for the order task; in Experiment 4, Ms = 
Table 7

Mean Reaction Times (in Milliseconds) and Percentages of Errors for the Replacement Pairs in Experiment 3, as a Function of Task, Permutation, Spacing Condition (No Space, Space), and Replacement Position (Left, Center, Right)

\begin{tabular}{|c|c|c|c|c|c|c|}
\hline \multirow{3}{*}{$\begin{array}{c}\text { Task and } \\
\text { Permutation }\end{array}$} & \multicolumn{6}{|c|}{ Replacement Position } \\
\hline & \multicolumn{3}{|c|}{ No-Space Condition } & \multicolumn{3}{|c|}{ Space Condition } \\
\hline & Left & Center & Right & Left & Center & Right \\
\hline \multicolumn{7}{|c|}{ Reaction Times } \\
\hline \multicolumn{7}{|l|}{ Order } \\
\hline$A B C$ & 596 & 673 & 752 & 603 & 626 & 813 \\
\hline ACB & 560 & 628 & 653 & 547 & 567 & 635 \\
\hline BAC & 596 & 613 & 563 & 620 & 536 & 548 \\
\hline BCA & 546 & 633 & 634 & 532 & 588 & 560 \\
\hline $\mathrm{CAB}$ & 608 & 556 & 559 & 546 & 534 & 562 \\
\hline CBA & 622 & 561 & 586 & 563 & 537 & 575 \\
\hline \multicolumn{7}{|l|}{ Item } \\
\hline $\mathrm{ABC}$ & 785 & 790 & 861 & 783 & 801 & 843 \\
\hline ACB & 914 & 785 & 862 & 892 & 733 & 830 \\
\hline BAC & 996 & 770 & 902 & 959 & 786 & 806 \\
\hline BCA & 818 & 802 & 868 & 812 & 847 & 805 \\
\hline $\mathrm{CAB}$ & 841 & 797 & 895 & 828 & 726 & 867 \\
\hline CBA & 838 & 745 & 820 & 848 & 694 & 763 \\
\hline \multicolumn{7}{|c|}{ Percentage of Errors } \\
\hline Order & & & & & & \\
\hline $\mathbf{A B C}$ & 1.2 & 7.5 & 8.7 & 2.5 & 3.7 & 10.0 \\
\hline ACB & 0.0 & 0.0 & 1.2 & 1.2 & 1.2 & 1.2 \\
\hline BAC & 1.2 & 1.2 & 3.7 & 1.2 & 1.2 & 0.0 \\
\hline $\mathrm{BCA}$ & 2.5 & 6.2 & 6.2 & 5.0 & 2.5 & 3.7 \\
\hline $\mathrm{CAB}$ & 3.7 & 2.5 & 1.2 & 3.7 & 1.2 & 5.0 \\
\hline CBA & 0.0 & 3.7 & 5.0 & 3.7 & 1.2 & 0.0 \\
\hline \multicolumn{7}{|l|}{ Item } \\
\hline $\mathrm{ABC}$ & 1.2 & 7.5 & 3.7 & 0.0 & 2.5 & 5.0 \\
\hline ACB & 6.2 & 1.2 & 0.0 & 8.7 & 2.5 & 2.5 \\
\hline BAC & 8.7 & 1.2 & 1.2 & 11.2 & 5.0 & 2.5 \\
\hline $\mathrm{BCA}$ & 6.2 & 1.2 & 6.2 & 2.5 & 6.2 & 7.5 \\
\hline $\mathrm{CAB}$ & 3.7 & 1.2 & 8.7 & 7.5 & 3.7 & 6.2 \\
\hline CBA & 2.5 & 1.2 & 2.5 & 0.0 & 2.5 & 7.5 \\
\hline
\end{tabular}

881,801 , and $882 \mathrm{msec}$ for the left, center, and right positions in the item task, and 602,605 , and $651 \mathrm{msec}$ in the order task).

Additionally, the replacement position $\times$ base permutation interaction $\left[F_{3}(10,600)=10.3, p<.001\right.$; $\left.F_{4}(10,600)=6.63, p<.001\right]$ was significant, as was the three-way interaction of these variables with task in Experiment $3\left[F_{3}(10,600)=3.50, p<.001\right]$. The latter two interactions show that the replacement patterns evident in the order and item tasks did not hold for all permutations.

For the error data, the main effect of base permutation $\left[F_{3}(5,300)=2.66, p<.03 ; F_{4}(5,300)=4.76, p<.001\right]$, the task $\times$ base permutation interaction $\left[F_{3}(5,300)=2.68\right.$, $\left.p<.03 ; F_{4}(5,300)=5.73, p<.001\right]$, and the replacement position $\times$ base permutation interaction $\left[F_{3}(10,600)\right.$ $\left.=3.39, p<.001 ; F_{4}(10,600)=3.31, p<.001\right]$ were significant. The effect of base permutation was not consistent across the two experiments $\left(\mathrm{ABC}, P E_{3}=4.4, P E_{4}\right.$ $=7.1 ; \mathrm{ACB}, P E_{3}=2.2, P E_{4}=5.2 ; \mathrm{BAC}, P E_{3}=3.2$, $P E_{4}=5.4 ; \mathrm{BCA}, P E_{3}=4.7, P E_{4}=3.6 ; \mathrm{CAB}, P E_{3}=$ 4.1, $P E_{4}=3.3$; and CBA, $P E_{3}=2.5, P E_{4}=3.7$ ). Moreover, within each experiment, the pattern was not consistent across tasks or replacement positions.
In addition to the findings that were significant in both experiments, Experiment 4 showed main effects of task $\left[F_{4}(1,60)=6.95, p=.01\right]$ and replacement position $\left[F_{4}(2,120)=7.74, p<.001\right]$, as well as a three-way interaction of task $\times$ space/filled $\times$ base permutation $\left[F_{4}(5,300)=2.41, p<.05\right]$. The order task $(P E=3.2)$ was more accurate than the item task $(P E=6.1)$. Accuracy was a $U$-shaped function of replacement position $(P E s=4.6,3.5$, and 6.0), and this function varied across permutations. Finally, the inclusion of the asterisks between the letters increased errors for some permutations and decreased them for others, with the patterns of effects differing across the two tasks.

\section{Discussion}

Increasing the separation of the component letters within the letter strings by inserting spaces had no significant effect on performance; the displacement and serial-position effects observed in Experiments 1 and 2 were still evident. When asterisks were placed between the letters, these effects were exaggerated. However, the influence of the asterisks was equivalent for the order and item tasks. Thus, neither manipulation produced dissociations between the two tasks.

Table 8

Mean Reaction Times (in Milliseconds) and Percentages of Errors for the Replacement Pairs in Experiment 4, as a Function of Task, Permutation, Spacing Condition (Space, Filled), and Replacement Position (Left, Center, Right)

\begin{tabular}{|c|c|c|c|c|c|c|}
\hline \multirow{3}{*}{$\begin{array}{l}\text { Task and } \\
\text { Permutation }\end{array}$} & \multicolumn{6}{|c|}{ Replacement Position } \\
\hline & \multicolumn{3}{|c|}{ Space Condition } & \multicolumn{3}{|c|}{ Filled Condition } \\
\hline & Left & Center & Right & Left & Center & Right \\
\hline \multicolumn{7}{|c|}{ Reaction Times } \\
\hline Order & & & & & & \\
\hline ABC & 586 & 638 & 702 & 634 & 736 & 864 \\
\hline $\mathrm{ACB}$ & 559 & 627 & 643 & 581 & 627 & 757 \\
\hline BAC & 617 & 555 & 555 & 648 & 579 & 657 \\
\hline BCA & 596 & 609 & 581 & 615 & 600 & 642 \\
\hline $\mathrm{CAB}$ & 562 & 579 & 579 & 614 & 577 & 595 \\
\hline CBA & 589 & 564 & 621 & 615 & 565 & 613 \\
\hline \multicolumn{7}{|l|}{ Item } \\
\hline $\mathrm{ABC}$ & 823 & 816 & 866 & 847 & 799 & 898 \\
\hline $\mathrm{ACB}$ & 872 & 809 & 858 & 927 & 836 & 924 \\
\hline BAC & 960 & 790 & 893 & 1076 & 859 & 977 \\
\hline BCA & 819 & 822 & 800 & 898 & 874 & 886 \\
\hline CAB & 807 & 771 & 833 & 922 & 806 & 879 \\
\hline CBA & 778 & 705 & 896 & 843 & 716 & 864 \\
\hline \multicolumn{7}{|c|}{ Percentage of Errors } \\
\hline Order & & & & & & \\
\hline $\mathrm{ABC}$ & 2.5 & 5.0 & 7.5 & 2.5 & 7.5 & 21.2 \\
\hline $\mathrm{ACB}$ & 2.5 & 1.2 & 3.7 & 2.5 & 3.7 & 10.0 \\
\hline BAC & 2.5 & 1.2 & 0.0 & 1.2 & 0.0 & 1.2 \\
\hline BCA & 2.5 & 3.7 & 2.5 & 1.2 & 3.7 & 0.0 \\
\hline $\mathrm{CAB}$ & 2.5 & 0.0 & 2.5 & 3.7 & 1.2 & 0.0 \\
\hline CBA & 1.2 & 1.2 & 2.5 & 6.2 & 3.7 & 2.5 \\
\hline \multicolumn{7}{|l|}{ Item } \\
\hline $\mathrm{ABC}$ & 6.2 & 7.5 & 8.7 & 2.5 & 7.5 & 6.2 \\
\hline $\mathrm{ACB}$ & 5.0 & 6.2 & 11.2 & 10.0 & 1.2 & 6.2 \\
\hline BAC & 10.0 & 6.2 & 7.5 & 18.7 & 5.0 & 11.2 \\
\hline BCA & 2.5 & 3.7 & 8.7 & 2.5 & 5.0 & 6.2 \\
\hline $\mathrm{CAB}$ & 7.5 & 0.0 & 7.5 & 6.2 & 2.5 & 5.0 \\
\hline CBA & 2.5 & 2.5 & 2.5 & 5.0 & 3.7 & 10.0 \\
\hline
\end{tabular}


These findings are particularly striking for the order task, because, even though between-position comparisons are unnecessary, separating the letters did not prevent the comparisons from being made. This is evident in that the position effects remained for that task when the display items were separated. Moreover, these effects were enhanced, rather than reduced, for the RT measure when extraneous symbols were included. Thus, Experiments 3 and 4 provide no evidence that the weightings assigned to between-position comparisons can be controlled to prevent these comparisons even when they are irrelevant.

\section{GENERAL DISCUSSION}

Studies of pattern matching have shown that processes other than the settings of response criteria seem to be relatively inflexible. However, results suggesting that alternative strategies may be available during the matching process were obtained by Proctor and Healy $(1985,1987)$. They demonstrated distinct serial-position effects within the order and item tasks for pairs of letter strings that contained the same letters in different orders, and for pairs in which one letter had been replaced. To explain these results, Proctor and Healy appealed to the notion that the two tasks induced different weightings of the serial positions in the strings. They also suggested that subjects may be able to control these weightings according to the task demands.

In the present experiments, we investigated the extent to which subjects can control within- and between-position comparisons. This distinction is important, because withinposition comparisons are pertinent in the order task but between-position comparisons are not. Thus, manipulations designed to influence within- and between-position weightings should have distinctly different effects on the order and item tasks if those weightings are changeable.

In Experiments 1 and 2, we manipulated the proportions of trials on which a mismatching letter appeared in the left, center, or right position. Positional bias had little effect on performance and did not interact significantly with the type of task on any measure. In Experiments 3 and 4 , we varied the spacing between letters, as well as whether or not the spaces were filled by extraneous characters. The spacing manipulation had no effect for either task; the extraneous characters actually served to exaggerate the displacement effects already present for RT and did so equivalently for the two tasks. Therefore, all of the experiments provide little evidence that subjects can control the weightings given to either within- or betweenposition comparisons, even when those comparisons are unnecessary.

Ratcliff (1988) performed an experiment in which the spacing between letters was manipulated within trials. The first string consisted of three letters in the center of five positions. The letters for the second string were presented in any three of the five positions. All subjects performed under order-relevant instructions. Consonant with the present Experiment 3, the rearranged pairs and replace- ment pairs showed no effect of the spacing manipulation. Thus, as in our experiment, the additional spaces did not influence the weightings of the between-position comparisons.

In contrast with the results of Experiment 3, Ratcliff (1988) observed a small, but significant effect of spacing on same RTs to the identical pairs. RT was fastest and accuracy greatest when the letters for the second string were in the same positions as those for the first. Performance was sightly worse when a single space intervened between one or more of the letters, and worst when two spaces separated one letter from the other two. In Experiments 3 and 4 of the present study, the spacing was the same for the second string as for the first string. In the no space condition, there were no spaces between letters in either string, while in the space condition, there were two spaces between the letters in both strings. Thus, there were no mismatches between the two strings in terms of the spatial positions occupied by the letters. Such mismatches apparently produced the spacing effect observed in Ratcliff's experiment. Thus, his spacing manipulation apparently varied the effective similarity between the two identical strings, and the results are not inconsistent with our findings.

The fundamental assumption that guided the experiments reported in this paper has been that the distinct serial-position effects for the order and item tasks were due to different weightings of information sources in the comparison process. Such weighting differences were thought to be a function of processes that are under subjects' control. Consequently, the independent variable of positional probability used in Experiments 1 and 2 is known to affect processing strategies in similar tasks (e.g., those in Shaw, 1982, and Theios et al., 1973), as are the spacing variables used in Experiments 3 and 4 (Healy et al., 1987; Shaw, 1969). Yet these variables had only marginal influence on performance and affected the order and item tasks similarly. These null effects suggest that the distinct serial-position effects arise not from any taskspecific weighting strategy but rather from the different stimulus-response relations involved in the two tasks.

In contrast to the relative lack of effect of the variables designed to manipulate processing strategies, the task variable (order, item) has consistent and distinct effects on serial-position functions. These effects occur despite the fact that the order and item tasks differ only in terms of whether the rearranged pairs are assigned to the response "different" or "same." Given the substantial evidence from numerous variations of the matching task that many aspects of performance can be explained in terms of taskdetermined, response-selection factors, it seems best to conclude that the task-specific position effects also arise from response-selection factors. In other words, these effects are determined by the parameters of the tasks and not by any comparison strategy that is open to change.

It appears that manipulations intended to influence comparison strategies are not going to provide much information about the nature of the serial-position effects in 
the multiletter-matching task. Rather, because the effects seem to stem from the mappings of pair types to responses that are defined by the rules of the tasks, manipulations of the mappings are more likely to be fruitful avenues of research, as has been demonstrated for other choicereaction tasks (Proctor \& Reeve, 1990).

\section{REFERENCES}

Ambler, B. A., Proctor, J. D. (1976). The familiarity effect for single-letter pairs. Joumal of Experimental Psychology: Human Perception \& Performance, 2, 222-234.

ANgiolillo-Bent, J. S., \& RIPS, L. J. (1982). Order information in multiple-element comparison. Journal of Experimental Psychology: Human Perception \& Performance, 8, 392-406.

Carr, T. H., Posner, M. I., Pollatsek, A., \& Snyder, C. R. R. (1979). Orthography and familiarity effects in word processing. Journal of Experimental Psychology: General, 108, 389-414.

ERIKSEN, C. W., ERIKSEN, B. A. (1979). Target redundancy in visual search: Do repetitions of the target within the display impair processing? Perception \& Psychophysics, 26, 195-205.

Eriksen, C. W., O'Hara, W. P., \& ErIKSEN, B. A. (1982). Response competition effects in same-different judgments. Perception \& Psychophysics, 32, 261-270.

Healy, A. F., Conboy, G. L., Drewnowski, A. (1987). Characterizing the processing units of reading: Effects of intra- and interword spaces in a letter detection task. In B. K. Britton \& S. Glynn (Eds.), Executive control processes in reading (pp. 279-296). Hillsdale, NJ: Erlbaum.

Krueger, L. E. (1978). A theory of perceptual matching. Psychological Review, 85, 278-304.

KRUEGER, L. E. (1985). Effect of intermixed foveal and parafoveal presentation on same-different judgments: Evidence for a criterioninertia model. Perception \& Psychophysics, 37, 266-271.

Krueger, L. E., Chignell, M. H. (1985). Same-different judgments under high speed stress: Missing-feature principle predominates in early processing. Perception \& Psychophysics, 38, 188-193.

Proctor, R. W., Healy, A. F. (1985). Order-relevant and orderirrelevant decision rules in multiletter matching. Journal of Experimental Psychology: Learning, Memory, \& Cognition, 11, 519-537.

Proctor, R. W., \& HeAly, A. F. (1987). Task-specific serial position effects in comparisons of multiletter strings. Perception \& Psychophysics, 42, 180-194.

PROCTOR, R. W., RAO, K. V. (1983). Evidence that the same-different disparity in letter matching is not attributable to response bias. Perception \& Psychophysics, 34, 72-76.

Proctor, R. W., Rao, K. V., Hurst, P. W. (1984). An examination of response bias in multiletter matching. Perception \& Psychophysics, 35, 464-476.

Proctor, R. W., \& Reve, T. G. (1990). Stimulus-response compatibility: An integrated perspective. Amsterdam: North-Holland.

Proctor, R. W., Van Zandt, T., Watson, H. D. (1990). Effects of background symmetry on same-different pattern matching: A compromise-criteria account. Perception \& Psychophysics, 48, 543-550.

Proctor, R. W., WeEks, D. J. (1989). Instructional and probability manipulations of bias in multiletter matching. Perception \& Psychophysics, 45, 55-65.

RATCLIF, R. (1981). A theory of order relations in perceptual matching. Psychological Review, 88, 552-572.

RatCLIF, R. (1988). Order information and distributed memory models. In Proceedings of the Ninth Annual Conference of the Cognitive Science Society (pp. 474-486). Hillsdale, NJ: Erlbaum.

RATCUFF, R., HACKER, M. J. (1981). Speed and accuracy of same and different responses in perceptual matching. Perception \& Psychophysics, 30, 303-307.

SHAW, M. L. (1982). Attending to multiple sources of information: I. The integration of information in decision making. Cognitive Psychology, 14, 353-409.

SHAw, P. (1969). Processing of tachistoscopic displays with controlled order of characters and spaces. Perception \& Psychophysics, 6, 257-266.

Theios, J., Smith, P. G., Haviland, S. E., Traupmann, J., \& MoY, M. C. (1973). Memory scanning as a serial self-terminating process. Journal of Experimental Psychology, 97, 323-336.

VICKERS, D. (1979). Decision processes in visual perception. New York: Academic .Press.

WATSON, H. D. (1981). The effects of objective and perceived size properties on visual form matching. Joumal of Experimental Psychology: General, 110, 547-567.

(Manuscript received May 16, 1990; revision accepted for publication August 24,1990 .) 